\title{
Ranking of the Generic Abilities among Baby Boomer, Generation $X$, and Millennial Physical Therapists and Physical Therapy Students
}

Catherine D. Noonan

Campbell University, cnoonan@campbell.edu

Jennifer Bunn

Campbell University, jab229@shsu.edu

Heidi Shearin

Campbell University, shearin@campbell.edu

Follow this and additional works at: https://nsuworks.nova.edu/ijahsp

Part of the Interprofessional Education Commons, and the Physical Therapy Commons

This Manuscript has supplementary content. View the full record on NSUWorks here: https://nsuworks.nova.edu/ijahsp/vol17/iss4/7

\section{Recommended Citation}

Noonan CD, Bunn J, Shearin H. Ranking of the Generic Abilities among Baby Boomer, Generation X, and Millennial Physical Therapists and Physical Therapy Students. The Internet Journal of Allied Health Sciences and Practice. 2019 Jan 01;17(4), Article 7.

This Manuscript is brought to you for free and open access by the College of Health Care Sciences at NSUWorks. It has been accepted for inclusion in Internet Journal of Allied Health Sciences and Practice by an authorized editor of NSUWorks. For more information, please contact nsuworks@nova.edu. 


\title{
Ranking of the Generic Abilities among Baby Boomer, Generation X, and Millennial Physical Therapists and Physical Therapy Students
}

\begin{abstract}
Background: The events and social conditions experienced by a generational cohort are thought to shape values and behaviors. Numerous studies have correlated generational differences with unique professional behaviors and educational preferences. However, few studies have examined this theory in the practice of physical therapy. Purpose: The purpose of this study was to assess generational differences in ranking of the Generic Abilities, a tool for assessing professional behaviors, as used in physical therapy in the United States of America. Methods: An online survey including demographic information, region of residence, years of experience, and ranking of Generic Abilities was sent via email to clinical partners and diverse regional university physical therapy education programs. Comparisons of ranking between generations, sex, geographical region, years of experience, and practice setting were evaluated using a Kruskal-Wallis $\mathrm{H}$ Test. Results: Overall, all generations ranked professional behaviors similarly. Stress management was the only Generic Ability with a significant difference between generations $(p=0.001)$. Millennials ranked stress management higher than both Generation $X(p=0.010)$ and Baby Boomers $(p=0.023)$. There was a significant difference in rankings by years of experience for professionalism $(p=0.028)$ and stress management $(p=0.010)$. There was no statistical difference in rankings by sex, practice setting, race, educational and career status, or geographical region. Conclusion: With only one statistically significant exception, physical therapists and physical therapy students, regardless of generation, rank the Generic Abilities similarly, indicating that professional values may supersede those of a particular generation. Higher ranking of stress management among Millennials may indicate needs that impact career longevity. This knowledge can be utilized by educators and employers to implement strategies to improve success as younger generations progress through the work force.
\end{abstract}

\section{Author Bio(s)}

Catherine Noonan, PT, DPT, PCS, CEIM is an Assistant Professor in the Department of Physical Therapy at Campbell University. She is a board certified specialist in pediatric physical therapy.

Jennifer Bunn, PhD, is an Associate Professor and the Director of Research in the Department of Physical Therapy at Campbell University.

Heidi Shearin, PT, DPT, is an Assistant Professor and the Director of Clinical Education in the Department of Physical Therapy at Campbell University. 


\title{
1IVAHSP \\ The Internet Journal of Allied Health Sciences and Practice
}

Dedicated to allied health professional practice and education

Vol. 17 No. 4 ISSN 1540-580X

\section{Ranking of the Generic Abilities Among Baby Boomers, Generation X, and Millennial Physical Therapists and Physical Therapy Students.}

\author{
Catherine D. Noonan \\ Jennifer Bunn \\ Heidi Shearin \\ Campbell University \\ United States
}

\begin{abstract}
Background: The events and social conditions experienced by a generational cohort are thought to shape values and behaviors. Numerous studies have correlated generational differences with unique professional behaviors and educational preferences. However, few studies have examined this theory in the practice of physical therapy. Purpose: The purpose of this study was to assess generational differences in ranking of the Generic Abilities, a tool for assessing professional behaviors, as used in physical therapy in the United States of America. Methods: An online survey including demographic information, region of residence, years of experience, and ranking of Generic Abilities was sent via email to clinical partners and diverse regional university physical therapy education programs. Comparisons of ranking between generations, sex, geographical region, years of experience, and practice setting were evaluated using a Kruskal-Wallis H Test. Results: Overall, all generations ranked professional behaviors similarly. Stress management was the only Generic Ability with a significant difference between generations $(p=0.001)$. Millennials ranked stress management higher than both Generation $X(p=0.010)$ and Baby Boomers $(p=0.023)$. There was a significant difference in rankings by years of experience for professionalism $(p=0.028)$ and stress management $(p=0.010)$. There was no statistical difference in rankings by sex, practice setting, race, educational and career status, or geographical region. Conclusion: With only one statistically significant exception, physical therapists and physical therapy students, regardless of generation, rank the Generic Abilities similarly, indicating that professional values may supersede those of a particular generation. Higher ranking of stress management among Millennials may indicate needs that impact career longevity. This knowledge can be utilized by educators and employers to implement strategies to improve success as younger generations progress through the work force.
\end{abstract}

Keywords: physical therapy, Millennials, professionalism, allied health, health professions education 


\section{INTRODUCTION}

Success as a healthcare provider requires clinical skill and judgement, as well as behavioral skills that support and enhance the clinician-patient relationship, interprofessional relationships, career longevity, and job satisfaction. ${ }^{1,2}$ Behavior, and the values that underlie it, may be influenced by the events and social conditions that each generational cohort experiences, and generational differences can create both diversity and dissonance in the workplace. ${ }^{3,4}$ This study investigates differences in prioritization of professional behaviors, or Generic Abilities (GA), between generational cohorts in the field of physical therapy (PT).

The current generation working in healthcare includes Baby Boomers, born between 1946 and 1964, Generation Xers, born between 1965 and 1981, and Generation Y, or Millennials, born between 1982 and 2000.5,6 Baby Boomers are experiencing extended life expectancies over previous generations, and thus, are balancing adulthood while often caring for children and aging parents simultaneously. ${ }^{7,8}$ They grew up in a period of economic growth and are often described as workaholics. ${ }^{8}$ Generation Xers grew up during a period where single family homes were more common, technology expanded rapidly, and when family support became less important than strong friendships. ${ }^{8}$ The members of this group are often described as seeking balance between their work and personal lives. ${ }^{8}$ Millennials are categorized by family structures with two working parents, instant access to information through technology such as smartphones and social media, and being "ethnically diverse and globally aware."8 Millennials are defined by positive psychology, information technology, and innovation. ${ }^{9}$ They are both achievement- and service-oriented, and were reared in highly scheduled, structured environments. ${ }^{6}$ They are characterized as optimistic, possessing a view of the "big picture," valuing of teamwork, being narcissistic and, somewhat contradictorily, valuing service to others. ${ }^{10}$ Formative events of their generation include the September $11^{\text {th }}$ bombings and the rapid expansion of the Internet. Despite their differences, Millennials are described by some sources as having similar values and work ethic to Baby Boomers, but they may exhibit these values differently. ${ }^{7,11}$ Millennials tend to change jobs more frequently than other generational cohorts, often to advance, but remain in the same profession as long as other generations, work as many hours as other cohorts (all of whom are working more hours than they used to), and are especially drawn to organizations that promote social responsibility. 10,11,12 Like Generation Xers, Millennials place high value on aligning personal and professional life, but they may be particularly influenced by opportunities for advancement. 7,13

Some evidence suggests that communication styles and values differ between the generations in ways that may lead to misunderstanding or conflict in the workplace.3,4 Millennials expect frequent feedback and open communication from their supervisors, prefer to work in teams to avoid risk, and view a good relationship with their supervisor to be foundational to success. ${ }^{14-}$ ${ }_{16}$ Medical educators and employers perceive differences in learning styles and behavior between Millennials and other generations, and can view them as selfish, lazy, and unmotivated. ${ }^{17}$ Conversely, Millennial students believe that faculty need to engage students through shared responsibility in the educational approach and blending of traditional with active teaching methods. ${ }^{18}$

The purpose of this study is to determine if generational differences exist in ranking of the GA as used in PT. The GA were developed to identify and assess competence in key professional behaviors-commitment to learning, interpersonal skills, communication skills, effective use of time and resources, use of constructive feedback, problem-solving, professionalism, responsibility, critical thinking, and stress management-in the field of physical therapy (PT) in the United States (U.S.). ${ }^{1}$ The GA tool asks respondents to rate their competence in these abilities according to three criteria: 1 - Beginning Level, 3 - Developing Level, 5 - Entry Level. The GA tool (and its more modern partner, Professional Behaviors) is currently used in U.S. PT education programs as a tool for student advising, clinical preparation, and self-reflection. ${ }^{19}$ The GA were originally developed by May et al. in 1995 and revised in 2009.20,21 May's 2009 study indicated that the rank order of prioritization of these behaviors changed over time, but the study did not address generational differences. ${ }^{20,21}$ A 2003 study investigated the construct validity of the 10 original abilities and narrowed the list to seven (professionalism, critical thinking, professional development, communication management, personal balance, interpersonal skills, and working relationships), but also noted that $48 \%$ of the variance in professional behaviors was not accounted for by any of the described abilities. ${ }^{1}$

A 2018 study further reduced the list to five abilities (professionalism, problem solving, effective use of time and resources, interpersonal skills, and working relationships) to create a tool for identifying student physical therapists (SPT) with professional behavior concerns. ${ }^{19}$ The professional traits outlined in the GA have been identified as essential aspects of professionalism in other healthcare fields as well. ${ }^{1}$ Previous literature in other health professions fields has found generational difference in learning and the workplace and in prioritization of professional values, but PT has yet to address this issue with regards to Millennials. ${ }^{15,16,18,22}$ A 2007 study (Stumbo et al) examined prioritization of the behaviors (i.e., 1 is the most valued behavior and 10 is the least valued behavior) by physical therapists, analyzing the relationship between ranking of the abilities and generational cohort (Generation X and Baby Boomers) and found significant differences in prioritization only in the category of stress

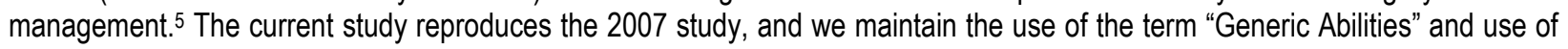


the original 10 items for consistency with the 2007 study. Notable changes are inclusion of the Millennial physical therapists and SPTs, many of whom are Millennials, and greater geographic diversity in sampling.

Though the Stumbo et al study drew responses primarily from the Midwest, we sought greater regional diversity, as regional characteristics differ. The U.S. Census Bureau divides the U.S. into four regions: Northeast (Connecticut, Maine, Massachusetts, New Hampshire, Rhode Island, Vermont, New Jersey, New York, and Pennsylvania); Midwest (Illinois, Indiana, Michigan, Ohio, Wisconsin, lowa, Kansas, Minnesota, Missouri, Nebraska, North Dakota, and South Dakota); South (Delaware, Florida, Georgia, Maryland, North Carolina, South Carolina, Virginia, District of Columbia, West Virginia, Alabama, Kentucky, Mississippi, and Tennessee, Arkansas, Louisiana, Oklahoma, and Texas); and West (Arizona, Colorado, Idaho, Montana, Nevada, New Mexico, Utah, Wyoming, Alaska, California, Hawaii, Oregon, and Washington). ${ }^{23}$ Population estimates (in number of people) for 2018 were as follows for the four regions: Northeast $(56,111,079)$; Midwest $(68,308,744)$; South $(124,753,948)$; and West $(77,993,663) .{ }^{24}$ The Northeast has the highest population density of the regions, while the West has the lowest. ${ }^{25}$ Demographic characteristics also differ between regions. Estimates of the percentage of the population over 18 years old indicate that the Northeast $(79.82 \%)$ and the South $(77.71 \%)$ are slightly older and the West $(76.72 \%)$ and Midwest $(76.86 \%)$ are slightly younger compared to the national average (77.6\%). ${ }^{26}$ The West region is more male, while the South is more female. ${ }^{27}$ According to 2010 census data, the Midwest is more white or Caucasian, while other regions are more racially diverse, though in distinct ways (for example, the South has a higher percentage of black or African American people while the West has a higher percentage of Alaskan or Native American people compared to other regions.) $)^{27}$ The South is disproportionately poor compared to the other three regions; three of the four poorest states in the U.S. are in the South. ${ }^{28}$

We hypothesized that rankings would be significantly different among Millennials because of influences on this generation-in particular, the vast proliferation of Internet-based technologies in their lifetime-that have changed the dynamics of control of and access to information and altered the ways in which people communicate with one another. We hypothesized that Millennials would rank effective use of time and resources, problem-solving, and critical thinking higher than would other generations, as a result of their reported characteristics of being tech-savvy, accustomed to easily-accessible and vast amounts of information, and their reputation as a highly-scheduled generation. We further hypothesized that they would rank professionalism and interpersonal skills lower than other generations, because of, respectively, purported lower prioritization of work over personal life and habits of connecting with others through the interface of technology. Because generational differences was the focus of our study, we did not generate hypotheses regarding other demographic or geographical factors and their impact on prioritization of the abilities.

\section{METHODS}

Study participants were recruited via email through clinical partners $(n=77)$ and university physical therapy education programs, including one small private and one large public university in each region $(n=84)$. Personnel at each site were asked to disperse the survey to their physical therapist contacts within their organization. After the initial close of the study, and given a limited number of responses in the West and Northeast regions, professional colleagues in those regions were sent the survey link again to attempt to elicit a greater number of responses. After final close of the survey, responses were reviewed and analyzed as described below. To best align with the 2007 Stumbo et al study, 1982 or later was determined as the cut point for Millennials. ${ }^{5}$

Survey items (see Appendix A) were created based on member demographic information provided by the American Physical Therapy Association (APTA), (including date of birth, sex, race, and ethnicity) as well as region of residence, years of experience, and ranking of GA (i.e. 1 is most important, 10 is least important). ${ }^{29}$ Region criteria-Northeast, Midwest, South, and West-were adopted from the U.S. Census Bureau. ${ }^{23}$ Participants provided consent and completed surveys via the online survey software Qualtrics (Provo, UT). The study was approved by the Institutional Review Board of Campbell University.

\section{Statistical Analysis}

Frequencies are reported for generation, sex, race, work experience, work setting, and region. Comparisons of GA ranking between generations, sex, geographical region, years of experience, and practice setting were evaluated using a Kruskal-Wallis $\mathrm{H}$ Test because the data are ordinal and not normally distributed. Upon significant main effect differences, Dunn-Bonferonni pairwise comparisons were used to reveal specific differences between groups. If the scores showed more than $25 \%$ ties between groups, an adjusted $\mathrm{H}$ was calculated and evaluated for statistical significance. ${ }^{30}$ Data are reported with median values. Alpha level was set at 0.05 to determine statistical significance. All data were analyzed using SPSS 19.0 (Chicago, IL). 


\section{RESULTS}

Not all SPTs at each program or all clinicians at each facility were contacted or chose to participate in the survey. We estimate that up to 9,300 students were contacted and up to 425 clinicians were contacted. A total of 181 participants consented for study participation, indicating a $1.9 \%$ return rate. Of these, 155 participants completed the survey. All statistics were completed using information from participants with completed surveys.

\section{Participant Demographics}

Table 1 illustrates the distribution of demographics for this study compared to representation within the APTA. ${ }^{20}$ The majority of the survey respondents had less than one year of experience $(n=68,43.8 \%)$-indicating they were either SPTs or newly licensed physical therapists-and the next highest responding group were those with 21-30 years of experience $(n=26,16.7 \%)$. Those with 6-10 and 11-15 years of experience each represented $9 \%$ of the study, with 14 respondents in both groups. Individuals with 31 or more years of experience $(n=9,5.8 \%), 4-5$ years of experience $(n=7,4.5 \%)$, and 1-3 years of experience $(n=4,2.6 \%)$ had the lowest representation. Thirteen participants did not report their experience. Most of the respondents for this study were younger and less experienced compared to demographics of APTA membership (1). By sex, the survey respondents were similar to APTA membership. Regionally, most of the respondents were from the South $(n=101,65.1 \%)$, followed by the Midwest $(n=$ $32,20.6 \%)$, the Northeast $(n=12,7.7 \%)$, and the West $(n=10,6.5 \%)$. The largest representation from practice settings were from academic institutions and "other" which both had 33 respondents, making up $21.3 \%$ each. Next were those working in a health system or hospital-based outpatient facility $(n=26,16.8 \%)$, followed by private outpatient office or group practice $(n=23,14.8 \%)$, and acute care hospital $(n=19,12.3 \%)$. The lowest respondents were from skilled nursing facilities $(n=9,5.8 \%)$, inpatient rehabilitation facilities $(n=7,4.5 \%)$, and school system $(n=2,1.3 \%)$. Three individuals chose not to provide this information. By educational and career status, the highest number of respondents were full time PTs $(n=90,58.1 \%)$, followed by SPT ( $n=59$, $38.1 \%)$ and part time PTs $(n=6,3.9 \%)$.

Table 1: Demographic information of survey respondents compared to members of the APTA

\begin{tabular}{|l|l|l|}
\hline & Number of Respondents (\%) & $\%$ of APTA Membership \\
\hline Baby Boomers & $11(7.1)$ & 36.4 \\
\hline Generation X & $52(33.5)$ & 34.6 \\
\hline Millennials & $92(59.3)$ & 29 \\
\hline Male & $45(29.0)$ & 30.1 \\
\hline Female & $110(70.9)$ & 69.9 \\
\hline American Indian or Alaskan Native & $0(0)$ & 0.8 \\
\hline Asian & $4(2.6)$ & 4.7 \\
\hline Black or African American & $6(3.9)$ & 1.2 \\
\hline Native Hawaiian or Pacific Islander & $2(1.3)$ & 0.3 \\
\hline Caucasian & $140(90.3)$ & 91.7 \\
\hline Other/Mixed & $3(1.9)$ & Not reported \\
\hline
\end{tabular}

\section{Group Differences}

Medians for each GA by generational group are reported in Table 2. There was no statistical difference in comparison of GA rankings by sex, practice setting, race, educational and career status, or geographical region. All three generational cohorts prioritized GA in nearly identical order (from most highly valued to lowest): communication, interpersonal skills, professionalism, critical thinking, problem solving, commitment to learning, responsibility, effective use of time and resources, use of constructive feedback, and stress management. The only ability with a significant difference between generations was stress management $(H(3)=18.919, p=0.001)$. Pairwise comparisons indicated that Millennials significantly ranked stress management higher than both Generation X ( $p=0.010)$ and Baby Boomers $(p=0.023)$. Despite statistically significant higher ranking of stress management among Millennials, all three generational cohorts ascribed the least importance to this professional behavior. 
Table 2: Rankings of importance of Generic Abilities by generation

\begin{tabular}{|l|l|l|l|l|}
\hline Generic Ability & Millennials & Generation X & Baby Boomers & Sig (p-value) \\
\hline Communication Skills & 3 & 3 & 2 & 0.842 \\
\hline Interpersonal Skills & 3 & 3 & 3 & 0.857 \\
\hline Professionalism & 4 & 3.5 & 4 & 0.152 \\
\hline Critical Thinking & 4 & 4 & 5 & 0.455 \\
\hline Problem-Solving & 5 & 5 & 5 & 0.943 \\
\hline Commitment to Learning & 6 & 6 & 6 & 0.842 \\
\hline Responsibility & 6 & 6 & 7 & 0.937 \\
\hline Effective Use of Time and Resources & 7 & 7 & 8 & 0.451 \\
\hline Use of Constructive Feedback & 8 & 9 & 8 & 0.490 \\
\hline Stress Management & 9 & 10 & 10 & $0.001^{*}$ \\
\hline
\end{tabular}

* denotes statistically significant difference among groups.

There was a significant difference in rankings by years of experience for professionalism $(H(7)=15.690, p=0.028)$ and stress management $(H(7)=18.499, p=0.010)$, as shown in Table 3. However, pairwise comparisons did not show significant difference by specific groups (i.e., $<1$ year vs. 1-3 years vs. 5-10 years, etc.). This is likely due to the small $n$-size in certain groups (1-3 years, for example) compared to relatively larger $n$-size in others (for example, $<1$ year). There was no statistical difference in rankings by sex, practice setting, race, educational and career status, or geographical region.

Table 3: Rankings of importance of Generic Abilities by years of experience

\begin{tabular}{|l|l|l|l|l|l|l|l|l|l|}
\hline Generic Ability & $<1$ year & $1-3$ yrs & $4-5$ yrs & $\begin{array}{l}6-10 \\
\text { yrs }\end{array}$ & $\begin{array}{l}11-15 \\
\text { yrs }\end{array}$ & $\begin{array}{l}16-20 \\
\text { yrs }\end{array}$ & $\begin{array}{l}21-30 \\
\text { yrs }\end{array}$ & $31+$ yrs & $\begin{array}{l}\text { Sig (p- } \\
\text { value })\end{array}$ \\
\hline Commitment to Learning & 6 & 5.5 & 8 & 5 & 7 & 6 & 6 & 6 & 0.968 \\
\hline Interpersonal Skills & 3 & 3.5 & 3 & 5 & 4.5 & 2.5 & 3 & 3 & 0.318 \\
\hline Communication Skills & 2.5 & 2 & 4 & 4 & 2.5 & 2.5 & 3 & 3.5 & 0.463 \\
\hline $\begin{array}{l}\text { Effective Use of Time } \\
\text { and Resources }\end{array}$ & 7 & 5 & 8 & 6.5 & 6 & 7 & 8 & 8.5 & 0.845 \\
\hline $\begin{array}{l}\text { Use of Constructive } \\
\text { Feedback }\end{array}$ & 8 & 7.5 & 7 & 8.5 & 8.5 & 7.5 & 9 & 8 & 0.656 \\
\hline Problem-Solving & 5 & 2 & 6 & 5.5 & 4.5 & 4 & 5.5 & 3 & 0.539 \\
\hline Professionalism & 5 & 4 & 5 & 2.5 & 2 & 5 & 3 & 5.5 & $0.028^{*}$ \\
\hline Responsibility & 6 & 7.5 & 5 & 7 & 4 & 7 & 6.5 & 6.5 & 0.618 \\
\hline Critical Thinking & 4 & 6 & 5 & 4 & 3.5 & 3.5 & 4 & 4.5 & 0.909 \\
\hline Stress Management & 9 & 9.5 & 7 & 9 & 10 & 10 & 10 & 10 & $0.010^{*}$ \\
\hline
\end{tabular}

* denotes statistically significant difference among groups

Ranking of importance of Generic Abilities was different in the current study than in the 2007 Stumbo et al study, as shown in Table 4. Though both cohorts ranked communication skills, interpersonal skills, and critical thinking in their top four abilities, they did so in different order. Problem-solving, ranked as the second most important ability in 2007 , fell to the fifth most important ability in 2017. However, both cohorts ranked effective use of time and resources, use of constructive feedback, and stress management, in that order, as the least three important abilities.

Table 4: Comparison of rank order of Generic Abilities (most valued to least valued)

\begin{tabular}{|l|l|}
\multicolumn{1}{|c|}{ Current Study } & \multicolumn{1}{c|}{ Stumbo et al 2007 } \\
\hline Communication Skills & Critical Thinking \\
\hline Interpersonal Skills & Problem-Solving \\
\hline Professionalism & Interpersonal Skills \\
\hline Critical Thinking & Communication Skills \\
\hline Problem-Solving & Professionalism \\
\hline Commitment to Learning & Responsibility \\
\hline Responsibility & Commitment to Learning \\
\hline Effective Use of Time and Resources & Effective Use of Time and Resources \\
\hline
\end{tabular}




\begin{tabular}{|l|l|}
\hline Use of Constructive Feedback & Use of Constructive Feedback \\
\hline Stress Management & Stress Management \\
\hline
\end{tabular}

\section{DISCUSSION}

The results of this study suggest that professional values may trump generational characteristics, when it relates to the ranking of GA. ${ }^{5}$ We hypothesized that Millennial physical therapists and SPTs would rank effective use of time and resources, problem solving, and critical thinking higher, and professionalism and interpersonal skills lower than the other generational cohorts. However, our hypotheses were not supported. In fact, all three cohorts-Baby Boomer, Generation X, and Millennial-ranked the abilities in nearly identical order. Communication skills and interpersonal skills, followed by professionalism, were the top three behaviors prioritized by each generational cohort. Critical thinking and problem solving were ranked fourth or fifth by each cohort, and effective use of time and resources were ranked relatively lower (seventh or eighth) for all cohorts. Stress management, the only behavior for which there was statistically significant difference in ranking, was ranked lowest by all three cohorts.

Though all groups rated stress management as their least important ability overall, Millennials' ranking of this value was statistically significantly higher than either Generation X or Baby Boomer participants, despite the fact that later revisions of the GA eliminated the stress management ability. ${ }^{19,21} \mathrm{~A}$ decade ago, stress management seemed to be of higher importance to the newer generation (then, Generation X) of physical therapists as well. ${ }^{5}$ However Millennials may experience stress for different reasons. A sheltered, structured upbringing may have deprived some Millennials of the skills of problem-solving and patience necessary for the development of resilience. ${ }^{6}$ Millennials may also suffer from what they perceive as a lack of support or barriers to advancement. Nursing and medicine students entering the workforce expected a supportive work environment and speedy advancement. ${ }^{17,22}$ Meanwhile professional nurses cited lack of support and lack of advancement opportunities as reasons for leaving positions, while workplace stress and a negative work environment were shown to correlate with intention to leave the workplace among physical therapists. ${ }^{13,23}$ As a cohort, Millennials tend to be group-oriented and have been taught to value teamwork. ${ }^{10}$ Operating as an individual in a highly responsible role, after an educational trajectory with a strong emphasis on group work, may also produce anxiety. ${ }^{22}$

Viewed differently, statistically higher prioritization of stress management among the Millennial cohort may reflect attempts to achieve a balance between personal and professional life for early-career practitioners.7,13,17 In the current study, stress management was ranked highest among those practitioners who had been practicing between four and five years. This may represent a phase of increased professional demand, impending burnout, or may represent individuals starting families. Such characteristics, however, were not assessed in this study and may be a valuable topic for future research.

While all three generations appear to prioritize professional behaviors similarly, they may manifest them differently. For example, when compared to older generations, Millennials' communication and interpersonal styles could be described as informal and regular. Millennials are more apt to engage with technology during personal interactions, which may be regarded as rude or disrespectful by older generations. ${ }^{17}$ Additionally, they expect relationships with authority figures to be similar to those which they have had with their parents: close, informal, supportive, non-hierarchical, and characterized by frequent, positive, concrete feedback. In contrast, other generations may see this style of interpersonal communication as too casual for the workplace. ${ }^{17}$

With regard to professionalism, medical educators expressed concerns about medical residents' lack of work ethic or understanding of personal sacrifice for the betterment of others. ${ }^{17}$ Millennial residents, by contrast, are more concerned with a balance between personal and professional life-"making a life" versus "making a living"--partly in reaction to seeing their Boomer parents sacrifice for their careers only to face downsizing and lay-offs. ${ }^{17,25}$ They prioritize how an institution fits them, rather than how they fit the institution. ${ }^{17}$ Finally, Millennials expect to advance quickly, which contrasts with other generations' concepts of advancement after paying one's dues. ${ }^{25}$

Notably, rankings of the Generic Abilities-though similar among all generational cohorts in the current study-were different from those reported in the 2007 Stumbo et al study. In particular, analytical skills (problem solving and critical thinking) were more highly valued among the 2007 study participants, while so-called "soft skills" (communication and interpersonal skills) were more highly valued among the current study's participants. Given the current ease of communication and connectivity facilitated by the Internet, smart phones, and social media, these rankings could reflect a more connected modern world, or in direct contrast, perceptions of a world in which interpersonal communication has suffered from reliance on digital devices. Finally, given the large proportion of Millennials queried in the current study, our findings may reflect skewed prioritization of communication skills resulting from Millennials' reported desire for open and frequent communication. ${ }^{14}$ 


\section{LIMITATIONS}

The limitations of this study include a relatively small sample size-especially in newer practitioners (practicing 1-3 years) and those practicing over 30 years, Baby Boomers, American Indians, Alaskan Natives and Asians-and limited geographic representation from West and Northeast regions.

\section{CONCLUSION}

The results of our study indicate that with only one statistically significant exception, physical therapists and SPTs, regardless of generation, rank the GA similarly. Statistically significant differences in ranking of stress management among generational cohorts may be a result of qualities specific to Millennials, lack of experience and trepidation associated with beginning a new career, or other factors not captured in this study. Regardless of provenance, however, the ability to manage stress is essential to career longevity. With this in mind, educators can build learning experiences that assist Millennial learners with stress management, including facilitating resilience through opportunities for failure, self-reflection and problem-solving; promoting the formation of social support systems among students and between students and faculty; adopting "transition" or mentoring programs that assist students in preparing for transition to independent work, including real or simulated experiences in the work environment that address both clinical and interpersonal skills; providing a mix of independent and group learning activities; and collaborating with counseling services to provide instruction on healthy stress management. 5,6,26 Millennials' work-related values as students are not significantly different from their work-related values as employees. ${ }^{27}$ Thus, employers may wish to design similar experiences as those noted above and nurture work cultures where teamwork, mentorship, cooperation, innovation, change, personal growth and flexibility are incentivized in order to enhance stress management and encourage retention for their Millennial employees. $6,11,22,26,27,28$ Workplace policies can incentivize healthy behaviors such as exercise, which also reduce stress. ${ }^{11,29}$

This study adds to the current literature by examining differences in prioritization of professional behaviors among generational cohorts of physical therapists and SPTs - an area that is not well represented in the literature, but which may improve educational and employment outcomes for the next generation of physical therapists. It indicates, in conjunction with the results of a study a decade earlier, that early career physical therapists and SPTs may be challenged to manage stress, but that overall, the values of the physical therapy profession span generations and may trump generational differences. In short, we may be more alike than we think.

\section{CONFLICT OF INTEREST: None reported}

\section{REFERENCES}

1. Jette D, Portney L. Construct validation of a model for professional behavior in physical therapist students. Physical Therapy. 2003;83(5):432-443.

2. Shacklock $\mathrm{K}$, Brunetto $\mathrm{Y}$. The intention to continue nursing: work variables affecting three nurse generations in Australia. Journal of Advanced Nursing. 2012;68(1):36-46.

3. Jones LM. Strategies for retaining a multigenerational workforce. J Bus Fin Aff. 2017;6: 271. doi: 10.4172/21670234.1000271.

4. DeMeulenaere K, Boone C, Buyl T. Unraveling the impact of workforce age diversity on labor productivity: The moderating role of firm size and job security. Journal of Organizational Behavior. 2016;37:193-212.

5. Stumbo T, Thiele A, York AM. Generic Abilities as rank ordered by Baby Boomer and Generation X Physical Therapists. Journal of Physical Therapy Education. 2007;21:48.

6. Bland HW, Melton BF, Welle P, Bigham L. Stress tolerance: new challenges for millennial college students. College Student Journal. 2012;46:362.

7. LeVasseur S, Wang C, Mathews B, Boland M. Generational differences in registered nurse turnover. Policy, Politics, \& Nursing Practice. 2009;10(3):212-223.

8. Fingerman K, Pillemer K, Silverstein M, Suitor J. The Baby Boomers' intergenerational relationships. The Gerontologist. 2012;52(2):199-209.

9. Graen G, Grace M. Positive industrial and organizational psychology: designing for tech-savvy, optimistic, and purposeful millennial professionals' company cultures. Industrial and Organizational Psychology. 2015;8:395-408.

10. Ferri-Reed J. Millennials - generation "screwed" or generation "shrewd?" The Journal for Quality and Participation. 2013;36(1):22.

11. Deal J, Altman D, Rogelberg S. Millennials at work: What we know and what we need to do (if anything). Journal of Business and Psychology. 2010;25(2):191-199.

12. Myers KK, Sadaghiani K. Millennials in the workplace: A communication perspective on Millennials' organizational relationships and performance. Journal of Business and Psychology. 2010;25:225-238. 
13. Tourangeau A, Cranley L. Nurse intention to remain employed, understanding and strengthening determinants. Nursing and Healthcare Management and Policy. 2006:55(4):497-509.

14. Society for Human Resource Management (SHRM). The multigenerational workforce: Opportunity for competitive success. http://www.shrm.org/Research/Articles/Articles/Documents/09-0027_RQ_March_2009_FINAL_noad.pdf. Accessed July 26, 2009.

15. Gursoy D, Maier TA, Chi CG. Generational differences: An examination of work values and generational gaps in the hospitality workforce. International Journal of Hospitality Management. 2008;27:458-488. doi: 10.1016/j.ijhm.2007.11.002.

16. Martin CA. From high maintenance to high productivity: What managers need to know about Generation Y. Industrial and Commercial Training. 2005;37:39-44. doi: 10.1108/00197850510699965.

17. Eckleberry-Hunt J, Tucciarone J. The challenges and opportunities of teaching "Generation Y". Journal of Graduate Medical Education. 2011;3(4):458-61.

18. Toothaker R, Taliaferro D. A phenomenological study of millennial students and traditional pedagogies. J Prof Nurs. 2017; 33(5):345-349. doi: 10.1016/j.profnurs.2017.01.004.

19. Dorsey L, Patrick K, Luetkemeyer P, Lojovich J. Use of an academic professional behavior assessment and intervention to promote professional socialization. Journal of Allied Health. 2018; 47 (3), 210-216C. [online]. http://search.proquest.com/docview/2114610737/. Accessed 2/28/19.

20. May WW, Morgan B, Lemke JC, et al. Model for ability-based assessment in physical therapy. Journal of Physical Therapy Education.1995;9(1):3-6.

21. Cahalin $\mathrm{L}$. The Linda Crane lecture professionalism and core values in physical therapy: lessons learned from Linda Crane. Cardiopulmonary Physical Therapy Journal. 2012 Jun; 23(2):30-39. https://www.ncbi.nlm.nih.gov/pmc/articles/PMC3379720/. Accessed 2/26/19.

22. Johnson M, Johnson L, ebrary I, Books24x7 I. Generations, inc: From boomers to linksters--managing the friction between generations at work. 1st ed. New York: AMACOM; 2010. Accessed 2/7/2018.

23. American Physical Therapy Association. 2014. Physical therapist member demographics profile 2013. http://www.apta.org/WorkforceData/DemographicProfile/PTMember/. Accessed 1/5/18.

24. United States Census Bureau. Census bureau regions and divisions with state FIPS Codes. Census.gov. https://www2.census.gov/geo/docs/maps-data/maps/reg_div.txt. Accessed 2/7/18.

25. U.S. Census Bureau, Population Division. Annual estimates of the resident population: April 1, 2010 to July 1, 2018. Release Dates: December 2018. https://factfinder.census.gov/faces/tableservices/jsf/pages/productview.xhtml?src=bkmk\#. Accessed 2/28/19.

26. U.S. Census Bureau. Geography: 2010 Population distribution in the United States and Puerto Rico. https://www.census.gov/geo/maps-data/maps/2010popdistribution.html. Accessed 2/28/19.

27. U.S. Census Bureau, Population Division. National population by characteristics: 2010-2018. Population estimates by age (18+): July 1, 2018 . https://www.census.gov/data/datasets/time-series/demo/popest/2010s-nationaldetail.html\#par_textimage_1223450682. Accessed 2/28/19.

28. U.S. Census Bureau. Census data mapper. Accessed from https://datamapper.geo.census.gov/map.html on 2/28/19

29. U.S. Census Bureau. Small area income and poverty estimates (SAIPE): 2017 All Ages in Poverty. https://www.census.gov/datatools/demo/saipe/saipe.html?s_appName=saipe\&map_yearSelector=2017\&map_geoSelector=aa_s\&s_state=\&s_mea sures=aa_snc. Accessed 2/28/19.

30. Portney LG, Watkins MP. Foundations of clinical research: applications to practice. $3^{\text {rd }}$ ed, 2015. F.A. Davis: Philadelphia.

31. Andrews DR. Expectations of millennial nurse graduates transitioning into practice. Nursing Administration Quarterly. 2013;37:152.

32. Lee B, Seo D, Lee J, Lee A, Jeon H, Han D. Impact of work environment and work-related stress on turnover intention in physical therapists. Journal of Physical Therapy Science. 2016;28:2358-2361.

33. $\mathrm{Ng}$ ES, Schweitzer L, Lyons ST. New generation, great expectations: A field study of the millennial generation. Journal of Business and Psychology. 2010;25(2):281-92.

34. Shatto B, Meyer G, Delicath TA. The transition to practice of Direct Entry Clinical Nurse Leader graduates. Nurse Education in Practice. 2016;19:97-103.

35. Kuron LKJ, Lyons ST, Schweitzer L, Ng ESW. Millennials' work values: differences across the school to work transition. Personnel Review. 2015;44:991-1009.

36. Liptrap S. Supporting millennials at work. Canadian HR Reporter. 2016;29:15

37. Watts AW, Laska MN, Larson NI, Neumark-Sztainer DR. Millennials at work: workplace environments of young adults and associations with weight-related health. Journal of Epidemiology and Community Health. 2016;70:65-71. 


\section{Appendix A: Survey Items}

1. Please select the choice below that most accurately describes your sex:

Male

Female

Transgender

2. Please select the choice below that most accurately describes your ethnic origin.

Hispanic or Latino

Not Hispanic or Latino

3. Please select the choice below that most accurately describes your race.

American Indian or Alaska Native
Asian
Black or African American
Native Hawaiian or Other Pacific Islander
White
Mixed Race

4. Please select the choice below that most accurately describes your current educational and career status.

Student physical therapist

Licensed physical therapist working full time

Licensed physical therapist working part time

Licensed physical therapist not currently working

5. Please select the choice below that most accurately describes your number of years you have been a practicing physical therapist. Student physical therapists, please select $<1$.
$<1$
$1-3$
$4-5$
$6-10$
$11-15$
$16-20$
20-30
$31+$

6. Please select the choice below that most accurately describes your practice setting.

Acute care hospital

Health system or hospital-based outpatient facility or clinic

Private outpatient office or group practice

Skilled Nursing Facility (SNF)/Long Term Care

Patient's home/home care

School system (preschool/primary/secondary)

Academic institution (post-secondary)

Health and wellness facility

Research center

Industry

Inpatient Rehab Facility (IRF)

Other (please specify)

7. Please enter the YEAR of your birth

8. Please indicate the geographic region of your permanent residence: 
NORTHEASTEAST (Includes Connecticut, Maine, Massachusetts, New Hampshire, Rhode Island, Vermont, New Jersey, New York, and Pennsylvania)

MIDWEST (Includes Illinois, Indiana, Michigan, Ohio, Wisconsin,

lowa, Kansas, Minnesota, Missouri, Nebraska, Northeast Dakota, and South Dakota)

SOUTH (Includes Delaware, Florida, Georgia, Maryland, Northeast Carolina, South Carolina, Virginia, District of Columbia, West Virginia, Alabama, Kentucky, Mississippi, and Tennessee, Arkansas, Louisiana, Oklahoma, and Texas)

WEST (Includes Arizona, Colorado, Idaho, Montana, Nevada, New Mexico, Utah, Wyoming, Alaska, California, Hawaii, Oregon, and Washington)

9. Please rank the Generic Abilities (listed below) in order of importance to you, with 1 indicating MOST IMPORTANT and 10 indicating LEAST IMPORTANT.

Commitment to learning

Interpersonal skills

Communication skills

Effective use of time and resources

Use of constructive feedback

Problem-solving

Professionalism

Responsibility

Critical thinking

Stress management 